\title{
Editorial
}

\section{When Colonoscopy Fails... Refer, Repeat, and Succeed}

\author{
Halim Awadie Michael J. Bourke \\ Gastroenterology and Hepatology Department, Westmead Hospital, Westmead, NSW, Australia
}

\section{Keywords}

Colonoscopy · Computed tomography colonography .

Advanced endoscopy

\section{Quando a Colonoscopia Falha... Referenciar, Repetir e Vencer!}

\section{Palavras Chave}

Colonoscopia · Colonoscopia virtual · Endoscopia avançada

In this issue of the journal, Ponte et al. [1] report important outcome data on repeat colonoscopy by an advanced endoscopist after a prior incomplete colonoscopy.

All experienced endoscopists are aware that colonoscopy may be very challenging, often for reasons that may not be immediately apparent, including normal anatomical variations between patients [2]. Incomplete colonoscopy should not be seen as a failure, as curtailing a procedure when progress stalls limits the risks of complications in a scenario where the prospects of clinical benefit to the patient are rapidly diminishing.

\section{KARGER}

E-Mail karger@karger.com www.karger.com/pjg
(C) 2018 Sociedade Portuguesa de Gastrenterologia Published by S. Karger AG, Basel

Karcer

Open access

This article is licensed under the Creative Commons AttributionNonCommercial-NoDerivatives 4.0 International License (CC BYNC-ND) (http://www.karger.com/Services/OpenAccessLicense). Usage and distribution for commercial purposes as well as any distribution of modified material requires written permission.
In this retrospective cohort study on the yield of colonoscopy completion by an advanced endoscopist after failed elective colonoscopy performed in the same department over 70 months until October 2016, 93 (1.5\%) of 6,196 patients had an incomplete colonoscopy. Indications were divided into surveillance (inflammatory bowel disease, previous cancer or polyp, family history screening) and investigation for symptoms (iron deficiency anaemia, abdominal mass, abdominal pain, change in bowel habits, inflammatory bowel disease assessment, diarrhoea, rectal bleeding, and abnormal colonic imaging). Reasons for incomplete colonoscopy were mainly looping and redundant colon (82.2\%) and suspected adhesions (15.1\%); hence, $78.5 \%$ of the procedures were aborted in the left colon.

Patients who had incomplete colonoscopy were referred to either computed tomography colonography (CTC), colonoscopy by an advanced endoscopist, or retrograde single balloon enteroscopy (SBE). Only $82.8 \%$ $(n=77)$ of patients had a second examination. The outcome for the additional 16 patients is not described, but is certainly important based on the literature and the findings of this study. CTC, colonoscopy by an advanced endoscopist, and SBE were performed in $45.5 \%(n=35)$,

Dr. Halim Awadie

Gastroenterology and Hepatology Department

Westmead Hospital

Westmead, NSW 2145 (Australia)

E-Mail halimawadie@gmail.com 
$53.2 \%(n=41)$, and $13 \%(n=10)$ of patients, respectively. After excluding two patients with incomplete second colonoscopy due to inadequate bowel preparation, the authors report a cecal intubation rate of $100 \%$. The second procedure identified no additional pathology (excluding diverticulosis) in $66.6 \%(n=56)$ of patients. One patient had suspected cancer on CTC, which was confirmed by surgery, while $11.7 \%(n=9)$ of the CTC group with suspected polyps were referred for colonoscopy or SBE as a third procedure.

Overall, advanced adenoma and cancer rate in patients who had colonoscopy or SBE were $26.5 \%$ (13) and $4.1 \%$ (2), respectively. The additional endoscopic procedure did not result in any complication but resulted in clinically important outcomes in 30\% of this group of patients. This is an important study, emphasizing again the utility of a repeat procedure by an advanced endoscopist after a prior failed colonoscopy. However, it is not clear what the considerations behind the choice of method for the second examination were. The sensitivity of CTC for polyps $\geq 6$ and $\geq 10 \mathrm{~mm}$ is 44 and $76.9 \%$, respectively [3]. Yet this method was selected for nearly half of the incomplete procedures. Of 35 patients who had CTC, $26 \%$ were referred to repeat colonoscopy or SBE for suspected polyp on CTC. These data suggest that CTC should not be the first option after failure of colonoscopy. CTC can be reserved for situations where there is a relative contraindication to colonoscopy or patient preference following detailed explanation of its limitations. Colon capsule shares similar limitations to CTC including the current relatively high polyp miss rate, lack of tissue resection and the need for repeat colonoscopy in patients with significant colonic findings.

Rex and colleagues from Indiana have published the largest cohort study on patients who were referred to a tertiary endoscopy unit after incomplete colonoscopy elsewhere [4]. In this very large study of 520 patients, cecal intubation rate was $97.3 \%$. They clearly show the high yield of additional pathology from repeat colonoscopy by an advanced endoscopist, with conventional adenoma, advanced adenoma, and cancer rates of 53,19 , and $1.7 \%$, respectively [4]. These authors have also summarised the 18 different studies of repeat colonoscopy in patients with prior incomplete colonoscopy. The success rate of cecal intubation ranges between 85.7 and $100 \%$ with adenoma detection rates between 11.8 and $54.2 \%$, in keeping with the data from the current study. There is large heterogeneity in study populations and endoscopic techniques with many studies of small volume (7-70) and often using balloon enteroscope or other special endoscopes [4-6].
Rex and colleagues clearly show that most repeat examinations can be safely completed with standard paediatric or adult colonoscopes, with gastroscopes used in $11 \%$, primarily in situations such as severe stenotic or fixed acutely angulated diverticular disease.

An important message from Ponte et al. [1] is the timing for repeat colonoscopy. The mean time between the index incomplete colonoscopy and the second examination was $6.73 \pm 11.88$ months. Although no prospective study has evaluated the importance of prompt referral for a second colonoscopy in incomplete procedures, we suggest that the second examination should be repeated in a similar time frame as suggested for incomplete colonoscopy due to inadequate bowel preparation being within 12 months [7] or sooner if there is high clinical suspicion of major pathology.

Incomplete colonoscopy may occur for a variety of reasons, the two most common being:

- Mobile and redundant left colon with loose mesenteric attachment.

- Severe stenosing sigmoid diverticulosis with or without previous pelvic surgery resulting in the additional challenge of relative colonic fixation and immobility. In such situations, it is not possible to safely "shorten the endoscope."

To optimise outcomes, all colonoscopists should master the art of insertion. It should be remembered that complete colonoscopy is achieved by shortening the colon over the colonoscope. The average length of the adult human colon, as measured by computed tomography, is $1.9 \mathrm{~m}$ with substantial propensity for further lengthening during intubation [8]. The colonoscope is 1.4-1.6 m; therefore, complete colonoscopy is not achieved simply by "pushing." Experienced operators consistently employ excellent fundamental techniques and a site-specific algorithmic approach to problem resolution [2]. Repeating the same manoeuvre more than twice rarely delivers success. Approximately two-thirds of the total insertion time should be spent in the left colon and the endoscope should be straight before passing the splenic flexure so that the remainder of the procedure will proceed smoothly [2].

A new consideration is the use of water immersion or exchange colonoscopy. Vemulapalli and Rex [9] have reported using the immersion technique in comparison to standard colonoscopy in patients with prior incomplete colonoscopy. They did not show any overall difference in cecal intubation rate; however, the need for external straightening devices and patient position changes in the water immersion group were significantly less. Further 
research is required to define those patients most likely to benefit from the water immersion technique.

In conclusion, basic colonoscopy insertion techniques should be mastered by all colonoscopists to minimise the frequency of incomplete colonoscopy and diminish the need for a repeat procedure, which is a cumbersome issue and time-consuming for both the patient and the health system. However, if progress stalls and consideration of a second examination is necessary, then this should be colonoscopy done by an advanced colonoscopist due to its safety, high yield for additional important pathology, and definitive outcomes.

\section{Disclosure Statement}

The authors have no conflicts of interest to declare.

\section{References}

1 Ponte A, Pinho R, Silva J, Rodrigues JP, Sousa M: High efficacy of repeating colonoscopy by an advanced endoscopist after an incomplete colonoscopy. GE Port J Gastroenterol 2018, DOI: $10.1159 / 000485803$.

$>2$ Bourke MJ, Rex DK: Tips for better colonoscopy from two experts. Am J Gastroenterol 2012;107:1467-1472.

$>3$ Weinberg DS, Pickhardt PJ, Bruining DH, Edwards K, Fletcher JG, Gollub MJ, et al: Computed tomography colonography vs colonoscopy for colorectal cancer surveillance after surgery. Gastroenterology 2017, DOI: 10.1053/j.gastro.2017.11.025.
Bick BL, Vemulapalli KC, Rex DK: Regional center for complex colonoscopy: yield of neoplasia in patients with prior incomplete colonoscopy. Gastrointest Endosc 2017;83:12391244.

$\checkmark 5$ Yamada A, Watabe H, Takano N, Yamaji Y, Yoshida H: Utility of single and double balloon endoscopy in patients with difficult colonoscopy: a randomized controlled trial 2013; 19:4732-4736.

6 Hotta K, Katsuki S, Ohata K, Abe T, Endo M: A multicenter, prospective trial of total colonoscopy using a short double-balloon endoscope in patients with previous incomplete colonoscopy. Gastrointest Endosc 2012;75: 813-818.
Lieberman DA, Rex DK, Winawer SJ, Giardiello FM, Johnson DA, Levin TR: Guidelines for colonoscopy surveillance after screening and polypectomy: a consensus update by the US Multi-Society Task Force on Colorectal Cancer. Gastroenterology 2012;143:844-857.

8 Khashab MA, Pickhardt PJ, Kim DH, Rex DK: Colorectal anatomy in adults at computed tomography colonography: normal distribution and the effect of age, sex, and body mass index. Endoscopy 2009;41:674-678.

9 Vemulapalli KC, Rex DK: Water immersion simplifies cecal intubation in patients with redundant colons and previous incomplete colonoscopies. Gastrointest Endosc 2012;76: 812-817. 